Falas de camarim:

história oral e história do teatro

\author{
Dressing room's talk: \\ oral history and theatre history
}

\title{
Tania Brandão
}

Tania Brandão

Professora colaboradora do Programa de

Pós-Graduação em Artes Cênicas da Unirio.

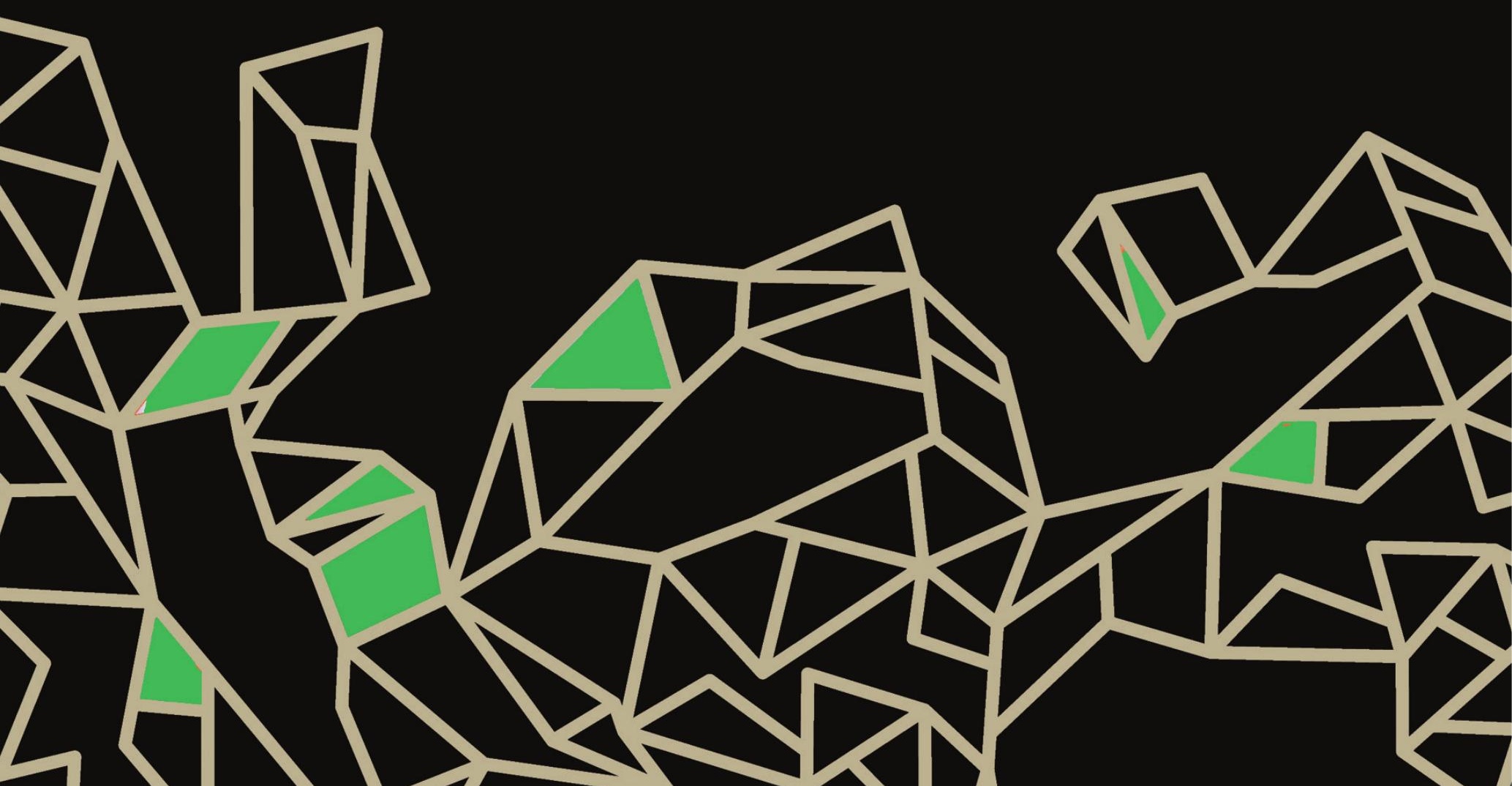




\section{Resumo}

Este artigo pretende demonstrar o papel fundamental da história oral para que se escreva a história da cena como história do palco. Longe da dramaturgia e da história da literatura, o texto propõe os conceitos de ícone da arte, história de vida e história da arte como ferramentas para a compreensão da complexa identidade dos atores e dos artistas de teatro. Nessa concepção, as entrevistas com artistas produzem fontes de pesquisa hábeis para iluminar o palco, mais do que qualquer outro documento possa fazer.

Palavras-chave: História oral, História da cena, Ícone da arte, História de vida, História na arte.

\section{Abstract}

This article seeks to explore oral history as the ideal way to write scene history as the history of the stage. Distant of dramaturgy and literary history, it proposes the concepts of art icon, life story and history of art as tools to understand the complex identity of actors and theatre artists. Within such conception, interviews with artists produce research sources able to illuminate the stage, more than any other document could do.

Keywords: Oral History, Scene History, Art icon, Life story, History in art.

Palavras, palavras, palavras: elas fervilham no teatro, volteiam por todo o espaço da arte. Apesar da força da mímica, da energia do corpo e do impacto do desenho de cena, a palavra se faz obrigatória - afinal, por tradição, a história do teatro a ela pertence. O mais notável é que essa palavra, tão obrigatória, matéria-prima da cena e da história do teatro convencional, é uma ferramenta hábil também para a construção da história da cena.

Quer dizer - a palavra é a materialidade dominante, no teatro ocidental, para a construção da cena. É a forma por excelência da obra de arte teatral enquanto arte viva. É matéria-prima da história do teatro. E, transmudada, é referência fundamental para que se escreva a história da cena na história do tempo presente: história oral da cena. O objetivo central deste texto é examinar 
a força da história oral para a escrita da história do teatro enquanto história da cena hoje, definir o seu alcance, expor o seu perfil conceitual e metodológico.

Falar em cena significa aqui traçar uma distância clara, ainda que ambígua, em relação à dramaturgia e à palavra escrita. A cena conta com uma fatura, um modo de operação encerrado em si. Boa parte dessa realidade de arte a que atribuímos o nome de cena se constrói como saber de coxia, oralidade, noções e modos de proceder transmitidos no campo de trabalho.

Apesar da existência de manuais técnicos, diários e das séries de informações pululantes na imprensa, o cerne da arte sobrevive no não dito em letras, parte de um rito de iniciados, segredo de arte. Fora dos registros formais, como é possível para o historiador o estudo da cena, esse não texto? Ao lado da realidade teatral, importa situar uma modalidade específica do saber histórico e estratégica para que se possa pensar a história da cena: a história do tempo presente.

A afirmação dos estudos históricos, em particular na França, no final do século XIX, exigiu, para sua consolidação, o combate a práticas amadoras, com a defesa de critérios rígidos e especializados de pesquisa. Tais critérios tinham como alicerce estratégico a documentação escrita, a recusa do uso de testemunhos e, portanto, em consequência, a exigência da especialização erudita, a recusa da hipótese de estudos do contemporâneo, avessos a tais métodos. Afirmava-se que, para o presente, a história não disporia da distância crítica essencial para a análise de fontes e fatos.

Apesar das transformações dos estudos históricos no século $X X$, da ruptura provocada pela École des Annales em relação à história política e factual dominante, só no final do século XX uma guinada decisiva da orientação dos estudos históricos trouxe novas perspectivas para o trabalho dos historiadores. Os novos caminhos nasceram do "aprofundamento das discussões acerca das relações entre passado e presente na história, e o rompimento com a ideia que identificava objeto histórico e passado" (FERREIRA, 2000, p. 117). A partir do fim da Segunda Guerra Mundial, várias expressões foram usadas para definir os estudos dedicados à história recente, vertente em franca expansão, mas de fronteiras cronológicas fluidas, objeto impreciso e metodologia vária. 
A denominação "história do tempo presente", de François Bédarida, ganhou força. Ela registra com clareza o interesse, outrora sem possibilidade de ser cogitado, de escrever a história atual, ainda que os marcos cronológicos para o novo campo de estudos persistam controversos. Um dos principais impulsos para a sua afirmação surgiu da constatação de que a visão do passado é construída "segundo as necessidades do presente" (FERREIRA, 2000, p. 117). Em consequência, não é estranho que se proponha como "marco" inaugural e diretriz para datação a visão a partir do presente. Assim, o marco pode ser um fato visto como inaugural, ou a vida de uma geração, cuja duração convencional é de sessenta anos.

Para a realização desses estudos e pesquisas, tornou-se imprescindível aceitar como fonte os testemunhos diretos, outrora renegados, desenvolvendo-se uma metodologia para dimensionar o alcance da presença da subjetividade, das distorções e das oscilações dos depoimentos - exatamente os atributos antes invocados para desqualificar o valor documental dos depoimentos. A palavra, ou antes a oralidade, tornou-se fonte - como acontecia nos primórdios da história. Agora, numa renovação metodológica profunda, esses atributos de desqualificação foram transformados, eles próprios, em objeto de pesquisa.

O tema aqui é objetivo, note-se - pretende-se discutir os caminhos para escrever a história da cena da nossa época sob um duplo desafio: história do presente e história da cena. E a atenção maior precisa incidir sobre o impasse primário - como fazer a história de uma arte que é sopro, fala? Por ironia, poderia aplicar ao caso o olhar platônico (PLATÃO, 1986, p. 121), segundo o qual a palavra imobilizada na escrita torna-se a perda de um saber, ensino morto?

Se, como sustenta o filósofo em Fedro, a palavra escrita deve ser em algum grau definida como uma espécie de palavra ignorante, um não saber, não seria fundamental, no estudo da arte em que a palavra é vida pulsante sempre, ter como fonte essa mesma condição do dizer? A palavra livre, liberta e aérea atesta sempre o conhecimento? Quais os limites, quais os desafios e quais os perigos da proximidade desse verbo fervilhante, pura emoção e sensibilidade, dissociado do logos e da busca do logos, para se chegar a uma inteligência a respeito da dinâmica da cena teatral? 
Vale retomar outro tema grego, a lenda de Eco e Narciso, na versão de Ovídio (CARVALHO, 2010, p. 100-105). Eco, uma bela ninfa, favorita de Diana, costumava acompanhá-la nas caçadas. Possuía um grave defeito - falava demais e sempre queria ter a última palavra. $O$ defeito serviu para que, sempre que Juno procurava surpreender Júpiter, quando ele copulava com as ninfas, Eco ocupasse a deusa com longas conversas, para as amigas fugirem. Ao perceber o estratagema, Juno decidiu puni-la. A partir de então, a ninfa passou a repetir apenas o final das frases ouvidas.

Ao ver, errando pelos campos, Narciso, Eco se perdeu de amores por ele. O destino de Narciso, segundo Tirésias, indicava uma vida longa desde que ele não conhecesse a si próprio. Apaixonada, Eco passou a segui-lo, sem coragem para abordá-lo, pois não poderia falar em primeiro lugar. Um dia o rapaz se perdeu dos colegas e começou a gritar por ajuda, recebendo de volta, de Eco, as palavras finais das suas falas. A ninfa se confundiu com o sentido de uma frase e abraçou o jovem, sendo repudiada. Desdenhada, ela se escondeu na selva, onde definhou e morreu, reduzindo-se a rochas, mas persistindo como viva voz.

O ser amado não teve sorte melhor - depois de desprezar muitos apaixonados, inconsciente do furor acionado por sua beleza, um deles suplicou por vingança e foi ouvido. Ao se dirigir a uma fonte límpida, Narciso viu a beleza incorpórea do próprio rosto na água e se apaixonou. Ainda que consciente de que se apaixonara por seu reflexo, ele não conseguiu romper o círculo e morreu à beira da fonte, dando vida a uma pequena flor.

O mito de Eco e Narciso importa para a fixação de alguns contornos para a pesquisa em teatro contemporâneo. De um lado, o pesquisador necessita localizar duas realidades opostas, mas complementares, interdependentes a realidade dos agentes da ação teatral, os atores e criadores, e a dos receptores, a plateia. Ou fãs...

Duas situações podem fazer a associação, no Brasil atual, ser questionada. Em primeiro lugar, o novo cânone da arte contemporânea, devotada ao experimental e ao performático - mas, por mais longe que se possa ter ido em nosso tempo na ousadia da criação, ainda persiste um polo de proposição, coadjuvado, nem que seja em pequena escala, por um polo de recepção. Ainda existe o Belo, de um lado, algo que se dá à contemplação para um outro, 
simples comentador, não formulador. A outra restrição situa a fraca força social do teatro hoje na sociedade, com os artistas tornando-se cada vez mais anônimos, distantes do mundo das celebridades. Mas, ainda aqui, persiste 0 Belo e, nem que seja no restrito círculo dos apaixonados por teatro, sobrevive a situação de consagração.

$\mathrm{Na}$ analogia com o mito, a obra de arte necessita saber de sua beleza e, para cumprir o seu destino, persistir para sempre encerrada em si, se construir como Belo, tornar-se flor - estado de belo natural. $\mathrm{O}$ amante da arte, por sua vez, ofuscado pelo brilho da criação, ecoa a obra, à qual se submete por denegação, para alienar-se de si e persistir para sempre enfeitiçado, como rochedo pulsante, mas sem vida. Assim, podemos representar o artista criador e seu público, a mecânica da arte na nossa sociedade.

Importa ir adiante. Ser artista significa construir uma bela imagem, uma imagem de ser diferente, personalidade criadora. Antes de se erigir como uma imagem pública, termo usual para a análise política, bem empregado por Peter Burke (1994) para o estudo de Luís XIV, o artista precisa se tornar ícone da arte - alguém que traz em si a aura mágica da criação, a energia pura do belo, sugestão imediata de arrebatamento, semelhante à sedução provocada por Narciso. Mas este elã precisa ser natural, inconsciente, digamos - a energia do artista deve fluir acima do imediato, etérea, como se fosse não um cálculo, um plano, mas uma força incontrolável imposta pelos deuses.

A noção de ícone da arte foi pensada a partir de Nathalie Heinich (1996). A autora dimensiona a ocorrência de uma valorização progressiva da criação nas sociedades ocidentais, a qual determina um deslizamento de sentido, a passagem do julgamento estético da obra para a pessoa do artista. Esse artista que pretende - e deve - se tornar célebre, precisa se revelar original e exprimir a sua interioridade de uma maneira tal que ela consiga atingir uma forma de universalidade.

Esse ícone da arte que se apresenta como uma entidade original e universal, capaz de irradiar sensações adequadas ao seu tempo, consegue, em consequência, captar o interesse dos contemporâneos. A construção do ícone da arte pressupõe a absorção da imagem da arte do tempo, a resposta às demandas e exigências feitas pela sociedade ao artista, o domínio e o diálogo com os cânones, com as ferramentas e com a tradição da arte. 
A abordagem proposta pode aflorar com nitidez graças à análise de alguns casos, legítimos ícones da arte com perfis irredutíveis um ao outro. Nos três casos, foram gravadas entrevistas de longa duração, com registro de voz e de imagem, elaboradas segundo procedimentos de história oral que serão expostos adiante.

As entrevistas de Maria Della Costa (1926-2015) e de Sandro Polônio (1921-1995) foram gravadas em Paraty, em 1995, na casa do casal, uma vivenda anexa à pousada que organizaram. De saída, um contraste marcava o casal - apesar de ter sido ator, diretor, iluminador e cenógrafo, Sandro se tornou empresário e produtor, em especial gestor e promotor da carreira da esposa.

Portanto, o tom predominante no ícone construído por Sandro era o do empreendedor, profundo conhecedor de toda a estrutura do fazer teatral. Apesar de sua intimidade com a realidade técnica e artística da caixa de palco, as suas maiores habilidades - e a sua paixão - surgiam ao descrever a rotina de manutenção da empresa teatral, papel que durante toda a entrevista buscou expor. Essas escolhas fizeram com que, durante a sua carreira, raramente ele fosse o foco de entrevistas.

Em consequência, a sua fala surgiu sempre cercada de certa aura de espanto ou surpresa, como se falar de si fosse coisa inusitada. E ele buscou refúgios de si, ao falar primeiro de Itália Fausta, sua tia, no início de sua carreira, e a seguir de Maria Della Costa, a estrela que ele batalhou para projetar. Não se percebeu na fala uma história de vida pessoal adequada a uma imagem da arte.

Maria Della Costa, ao contrário, evidenciou outra realidade. Integrante de uma geração de divas modernas, intérpretes marcadas por sua entrega à cena e por sua abolição de si diante do palco, contaminadas com certa mística cinematográfica, a atriz se apresentou sempre como ícone da arte, deusa da cena teatral moderna. Vale dizer: um moderno empreendedor, entregue ao inefável, mas consciente da realidade de trabalho, de produção. Diva moderna, aqui, equivale à diva despojada.

Assim, ao mesmo tempo que a estrela se revelava capaz de fazer e servir café e fazia questão de revelar que nunca se recusou a varrer palco ou 
passar figurino, ficou sempre clara a sua vaidade e a sua atenção à irradiação de sua aura de artista.

Maria Della Costa se apresentava, nas entrevistas, com uma aparência impecável - roupas elegantes e despojadas, originais, de artista, mas condizentes com a idade; maquiagem leve eficiente para destacar a beleza do rosto, em particular dos intensos olhos azuis; e cabelos revoltos próprios para compor o perfil e atenuar possíveis falhas geradas pela idade. A voz, o jeito de falar e de olhar, os gestos, toda a sua performance de sala, enfim, irradiavam doçura, bom humor e afabilidade - um jogo de sedução denso, contínuo, capaz de fazer com que o tempo passasse sem que se percebesse a sua ação.

$E$, ao falar de sua carreira, a revelação maior: não houve nenhuma contradição em todas as histórias, de vida ou na arte, que contou em tantas e tantas entrevistas ao longo da vida. Aliás, o mesmo dado despontou nas falas de Sandro Polônio. Eva Todor (1919-2017), artista da geração anterior, do chamado teatro do primeiro ator, desqualificado pelos modernos como "antigo", ao longo de vários depoimentos gravados em voz e em imagem teve desempenho semelhante, ou seja, manteve as mesmas histórias, de vida e na arte, contadas desde sempre para revistas, jornais, televisões, pesquisadores. A única diferença importante é a densidade do ícone - em Dona Eva, jamais a alma brejeira e buliçosa saiu de cena, jamais a encantadora Eva cedeu lugar a um ser identificado com as rotinas cotidianas ou qualquer outra realidade que não fosse estar-em-arte e conceder a entrevista.

Acrescenta-se um outro componente: nos arquivos doados pela Companhia Maria Della Costa ao Cedoc Funarte, foi localizado um conjunto de cadernos nomeado na pesquisa como Cadernos da Fã. Registros preciosos, foram produzidos por uma fã de Maria Della Costa, a Ditta de Jacareí, e indicam de forma contundente o olhar da fã para a estrela, a adoração automatizada, digna de Eco, essencial para dimensionar o ícone.

A partir dos exemplos, é possível estabelecer que o ícone da arte se constitui graças ao encontro entre suas histórias - de vida e história na arte - e é estruturado por um projeto artístico, que é sempre atualizado. A percepção do jogo só pode ser atingida por inteiro através de documentos orais falas diretas do artista, induzidas pelo pesquisador, conduzidas por perguntas 
elaboradas a partir de extenso levantamento de fontes e com a observação direta da performance de sala do artista.

Para o trabalho em história da cena, há um campo de pesquisa balizado por três tipos de documentos - escritos, imagéticos e orais. Os documentos orais e imagéticos são, em geral, vestígios primários, atuantes e diretos (BRANDÃO, 2009). São, também, os mais eficientes para que se dimensione a condição de ícone da arte. Os documentos orais, contudo, não são um terreno simples; eles apresentam formas contrastantes, as fontes orais e os documentos orais. Enquanto as fontes lidam diretamente com os fatos da fala e da estrutura do discurso, os documentos operam com a fixação de versões, fatos ou visões.

Os documentos orais, no seu sentido mais amplo, não são equivalentes simétricos da documentação escrita convencional, pois eles são (ou podem ser) produzidos pelo pesquisador. Portanto, na etapa da análise da documentação, as perguntas a fazer ao documento, o seu tratamento, a interpretação crítica e, afinal, o uso do material, são bem diferentes. Nada impede, contudo, o uso das entrevistas como mero registros, complementos simétricos às outras fontes convencionais.

Vale perguntar, então, o que é a fala para a construção da verdade histórica, a verdade da cena e a verdade do sujeito, do sujeito artista. Se a análise das fontes acontece apenas para estabelecer a verdade histórica, talvez seja bizarro adotar fontes tão diferentes como a documentação escrita, a oral e a imagética para contraprovas. Talvez a documentação oral fale, antes, de um outro lugar, o lugar da identidade do artista, do ícone da arte, do espaço das versões e não dos fatos.

Para a efetividade desses recursos, uma metodologia específica deve ser adotada, além da percepção da especificidade das histórias do teatro e da história da cena e da realidade objetiva do mundo dos artistas. Ela nasce da observação dos procedimentos adotados pelo Cedoc, da Fundação Getúlio Vargas (ALBERTI, 1990).

De saída, é preciso considerar que os documentos orais são entrevistas, ou seja, relatos conduzidos, estruturados segundo um conceito ou um objetivo. Não são depoimentos - relatos de formato livre, em que a liberdade e até mesmo a espontaneidade orientam o fluxo verbal, conforme o método 
preconizado por Maria Isaura Pereira de Queiroz. As entrevistas podem ser de dois formatos: a temática, para abordar um dado objetivo; e a de história de vida, cujo foco é o estudo pleno do artista abordado.

Em rigor, os mesmos procedimentos devem ser adotados para os dois tipos de entrevista, com maior extensão para a história de vida, cuja definição não é empírica; ela parte de uma visão sociológica (BOURDIEU, 1998) com a percepção da vida-trama, reunião de diversos agentes que obedece a uma estrutura de rede, na qual a personalidade é o conjunto de relações objetivas que uniram o agente considerado sob a abstração do nome. Acrescenta-se o fato de que o artista em geral apresenta dois nomes, duas identidades, para a necessária constatação da ampliação do número de agentes possíveis. A identidade do amplo jogo emerge da constatação de que o artista apresenta uma fala para a fama, uma versão de história de vida glamorizada, fincada no interior do seu mito pessoal - por isso as versões costumam se repetir ao longo da vida sem mudanças significativas. O mais importante, afinal, é a análise dessas linhas de estabilidade.

Para a elaboração dos roteiros de entrevista, um estudo de campo rigoroso precisa ser realizado. É necessário dispor de informação para lidar com o carisma e o elevado grau de subjetivismo do artista, perceber como a história de vida foi formulada para consolidar a imagem da arte, o cálculo por reconhecimento e por celebração, a materialização do ícone da arte. Não há, no artista, um projeto de vida e uma oralidade ingênuos, neutros, ou governados pelos jogos sociais correntes.

Por isso, estabelecer as histórias de vida e na arte através da documentação escrita e imagética é um passo essencial para a elaboração do roteiro de entrevista. Durante a entrevista, importa dispor de materiais de apoio bem estruturados - além dos roteiros, a cronologia de vida e obra, fotos, imagens e fichas técnicas. Após a realização da entrevista, a transcrição e a edição (a delicada e necessária passagem da fala para a escrita) exigem extremo cuidado do pesquisador - supõe-se que a documentação possa vir a ser uma fonte de pesquisa para a área de estudos, ainda que não disponhamos de centros de documentação em história oral consolidados para o teatro.

Ainda assim, existe uma longa lista de depoimentos e de memorialismo na história do teatro brasileiro. Além dos acervos jornalísticos, em que a ótica 
não é a arte, mas a opinião pública, existem incontáveis registros efetuados por pesquisadores e centros de documentação, os mais destacados sendo o Cedoc da Funarte e o extinto Idart, estruturado por Maria Tereza Vargas em São Paulo, hoje no Centro Cultural São Paulo.

Uma pequena parte dos depoimentos - e o nome é muito apropriado - realizados a partir da iniciativa do extinto Serviço Nacional de Teatro mereceu edição. O simples cotejo das publicações com as transcrições ou as fitas gravadas permite indiciar vários problemas metodológicos, conceituais e editoriais. Assim como acontece com extensa parte do trabalho desenvolvido por Brício de Abreu, o maior jornalista de teatro da história do país, esses materiais se constituem como fontes, mas exigem o exercício de uma crítica histórica severa.

Talvez não seja justo afirmar que o teatro e o palco, territórios dominados pela fala, pela palavra liberta da escravidão da escrita, reproduzida geração após geração em especial graças aos saberes de coxia, representem o lugar de elevação da alma e da libertação da mente humana proposto por Platão. Afirmar essa condição, recorrendo ao esforço pensante do filósofo em Fedro, seria um sofisma, uma demonstração por absurdo, por se pretender situar a Verdade na pulsação sensível, exatamente ali onde Platão afirma que ela não está.

Mas esse jogo de ideias não foi desenvolvido para brincar com o edifício grego ou para tentar atribuir ao teatro méritos que ele não tem. A razão de ser do jogo foi outra - ele surgiu apenas para procurar demonstrar como, no domínio da carne, da sensibilidade e da criação, é necessário e possível um rigor de pensamento, tensões e apropriações eficientes para fazer de uma arte evanescente realidade histórica, sem tentar contê-la na antiga forma apertada e de letras cansadas, a dramaturgia. Numa frase direta e curta, o que se desejou provar é que a história da cena teatral é um território sensível, afeito à história oral, campo liberto de velhas palavras ultrapassadas.

\section{Referências bibliográficas}

ALBERTI, V. História oral: a experiência do CPDOC. Rio de Janeiro: Editora da FGV/ CPDOC, 1990. 
BALME, C. Além do estilo: tipologias de análise da performance. Tradução Tania Brandão. O Percevejo, Rio de Janeiro, n. 7, ano 7, p. 132-143, 1999.

BOURDIEU, P. A ilusão biográfica. In: FERREIRA, M. de M.; AMADO, J. Usos e abusos da história oral. Rio de Janeiro: Fundação Getúlio Vargas, 1998.

BRANDÃO, T. Uma empresa e seus segredos: Companhia Maria Della Costa. São Paulo: Perspectiva, 2009.

BURKE, P. A fabricação do rei: a construção da imagem pública de Luís XIV. Rio de Janeiro: Zahar, 1994.

CARVALHO, R. N. B. Metamorfoses em tradução. 2010. 158 f. Tese (Pós-doutorado em Letras Clássicas) - Faculdade de Filosofia, Letras e Ciências Humanas, Universidade de São Paulo, São Paulo, 2010.

FERREIRA, M. M. (Coord.). Entre-vistas: abordagens e usos da história oral. Rio de Janeiro: Editora da Fundação Getúlio Vargas, 1994. p. 11. História do tempo presente: desafios. Cultura Vozes, Petrópolis, v. 94, n. 3, p. 111-124, maio/jun. 2000.

$\mathrm{HEINICH}, \mathrm{N}$. Être artiste: les transformations du statut des peintres et des sculpteurs. Paris: Klincksieck, 1996.

PLATÃO. Fedro ou Da beleza. Lisboa: Guimarães, 1986.

QUEIROZ, M. I. P. Variações sobre a técnica de gravador no registro da informação viva. São Paulo: T. A. Queiroz, 1991.

Recebido em 20/10/2017

Aprovado em 21/10/2017

Publicado em 26/12/2017 